OPEN ACCESS

Edited by:

Amre Nouh,

Hartford Hospital, United States

Reviewed by:

Christopher Lawrence Kramer,

University of Chicago, United States

Rick Gill,

Loyola University Chicago,

United States

*Correspondence:

Marie P. Brinckmann

marie-perle.brinckmann@charite.de

Specialty section:

This article was submitted to Neurocritical and Neurohospitalist

Care,

a section of the journal

Frontiers in Neurology

Received: 23 August 2018 Accepted: 28 November 2018 Published: 11 December 2018

Citation:

Brinckmann MP, van Noort BM, Leithner C and Ploner CJ (2018)

Neurological Emergencies in

Refugees. Front. Neurol. 9:1088.

doi: 10.3389/fneur.2018.01088

\section{Neurological Emergencies in Refugees}

\author{
Marie P. Brinckmann ${ }^{1 *}$, Betteke M. van Noort ${ }^{2}$, Christoph Leithner ${ }^{1}$ and \\ Christoph J. Ploner ${ }^{1}$
}

${ }^{1}$ Department of Neurology, Charité-Universitätsmedizin Berlin, Berlin, Germany, ${ }^{2}$ Department of Child and Adolescent Psychiatry, Psychosomatic Medicine and Psychotherapy, Charité-Universitätsmedizin Berlin, Berlin, Germany

Objective: Health care personnel in Europe is increasingly involved in care of displaced persons from non-European countries; we investigated the spectrum of neurological disorders and medical management in refugees presenting to the emergency room (ER) of a German university hospital.

Methods: We retrospectively studied ER-patients with refugee status (R-patients) during the peak of the European refugee crisis between July 2015 and February 2016 (N = 100). Complaints on admission, medical management and diagnoses at discharge were compared to matched groups of German residents with migrational background (M-patients; $N=96$ ) and to native Germans ( $N$-patients; $N=95$ ).

Results: R-patients were mostly male young adults (75\% male; mean age 33.2 years). Headache was the most frequent complaint in all groups (R-patients 38\%; M-patients 43\%; N-patients 24\%). R-patients, however, presented much more often with possible or definite seizures (R-patients 27\%; M-patients 9\%; N-patients 15\%). Initial triage, length of medical history and examination records, utilization of laboratory tests and cranial imaging did not differ between groups. However, time to diagnosis was considerably longer in R-patients (220 min; M-patients $151 \mathrm{~min}$, N-patients $123 \mathrm{~min}$ ). While strokes and other life-threatening emergencies were rare final diagnoses in R-patients, a substantial proportion was discharged with a diagnosis of non-epileptic seizures or a psychiatric disorder (20\%; M-patients 6\%; N-patients 7\%).

Conclusions: Refugee patients present with a spectrum of neurological disorders that not solely results from cultural differences but rather reflects the consequences of forced displacement. ER management of refugees requires more time, language skills and critically depends on psychosomatic/psychiatric expertise.

Keywords: emergency room, emergencies, refugees, migration, forced displacement, multicultural health care

\section{INTRODUCTION}

The growing number of refugees worldwide has developed into a major societal and health-care challenge, even in countries of the European Union (EU). Currently, there are 65.6 million forcibly displaced people worldwide. Among them, 5.6 million refugees are of Syrian and Afghan origin (1). In the recent few years, emergency rooms (ER) in the EU have been facing rising numbers of patients from Syria, Afghanistan, and Iraq seeking asylum-in particular in Germany (2). For example, in 2015, an estimated 90,000 refugees arrived in Berlin. Although refugee numbers from 
war-ridden countries have been slowly decreasing since the beginning of 2016, migration under precarious circumstances continues $(3,4)$. Health care personnel delivering care for refugees is facing challenges that result both from cultural differences and a lack of familiarity with the physical and psychological consequences of war, of a traumatizing journey and of involuntary relocation (5-7).

Apart from health care problems that are clearly attributable to war trauma, malnutrition, hygiene problems etc., previous studies suggested the possibility that forced migration may moreover induce a distinct spectrum of disorders that is not a mere consequence of cultural differences, but rather a signature of migration itself $(8,9)$. Several studies have observed that adversity suffered by refugees is associated to a particular range of neuropsychiatric conditions such as post-traumatic stress disorder, depression, and anxiety disorders (8-14). On the other hand, it has been claimed that a different cultural background may already account for significant differences in the spectrum of disorders found in migrants and residents in ERs (15). Since 2015, many hospitals in the EU have released volunteering doctors from regular clinical duties to provide basic medical care in refugee camps. However, data on the medical conditions refugees present with are scarce. It is currently unclear, whether the spectrum of diseases seen by emergency physicians in the EU reflects direct consequences of migration or merely results from cultural and demographical factors.

Here, we took the unique opportunity to gather data from neurological ER-Patients with refugee status in the largest university hospital in Europe. We investigated possible differences between the spectrum of neurological disorders in refugees and in age- and gender-matched controls with immigrant background and in patients with no immigrant background. We focused on the period from July 2015 to February 2016 that corresponded to the peak of refugee arrivals in Germany (16). Our main goal was to investigate whether there is a spectrum of neurological disorders that is directly related to refugee status. In addition, we aimed to characterize the resources necessary for an appropriate neurological emergency care in refugees.

\section{METHODS}

\section{Subjects}

For this study, we evaluated all patients with a refugee status who presented with neurological complaints to the ER of the Charité-Universitätsmedizin Berlin between the 1st of July, 2015 and 28th of February, 2016. This period corresponds to the peak of immigration to Germany during the Syrian Civil War. Refugee patients (R) were not selected by region of origin, but rather identified by manually selecting Arab, Pashto, and Dari surnames and screening the corresponding ER records. These three languages are spoken in Syria, Iraq, and Afghanistan, respectively (17), i.e., the homelands of the majority of nonEuropean refugees in Germany in 2015 (18). When a refugee status was not explicitly stated in the documents, the patient was not included. From the insurance status, place of residence and the medical histories it was obvious for each of the included Rgroup patients, that the duration of stay in Germany did not exceed some weeks prior to admission. Two groups of ageand sex-matched controls were selected from the same time period: A first group that consisted of patients with an immigrant background as identified by an Arab, Pashto or Dari surname and German residency of at least 2 years (M). Patients who did not speak German or with unclear duration of residency in Germany were not included. A second group of controls consisted of patients without immigrant background $(\mathrm{N})$, selected by their German first names and surnames. The study was conducted in accordance with the World Medical Association's Declaration of Helsinki and was approved by the Ethics committee of the Charité-Universitätsmedizin Berlin.

\section{Demographical and Clinical Variables}

The following variables were extracted from digital ER records: age, gender, main symptom on admission to the ER, initial medical triage, presence of an interpreter, compliance, length of medical history, and of physical examination, presence/absence of blood analyses, cranial imaging, and lumbar puncture. Furthermore, we determined diagnosis on discharge from the ER, time to diagnosis, treatment (medication), and the number of patients receiving further in-hospital treatment.

\section{Initial Medical Triage}

Prioritization for treatment was performed by using the Manchester Triage System (19) in almost all patients (missing values: R-patients 3; M-patients 3; N-patients 4). In the MTS version implemented in our hospital, patients are assigned by nursing staff to one of five possible priority classes on arrival at the ER, ranging from "red" (requires immediate treatment) to "blue" (should see a physician within $120 \mathrm{~min}$ ). We reasoned that between-group differences of this variable may reveal any positive or negative bias of the nursing staff toward the investigated patient groups.

\section{Compliance}

Compliance was rated as present or absent. Full compliance was assumed when the patient agreed on all diagnostic procedures and therapeutic suggestions of the ER neurologist. Refusal of diagnostic procedures (e.g., of a lumbar puncture) or of hospitalization was rated as non-compliance.

\section{Length of Medical History and Physical Examination}

The word counting tool in Microsoft Word was used to determine the length of medical histories and physical examination reports. We reasoned that this variable reflects the diligence of history taking in a given patient and may thus, indirectly, reveal any positive or negative bias of the ER neurologists toward the investigated patent groups.

\section{Blood Analyses, CT, MRI, Lumbar Puncture, and Administration of Medication}

These variables were rated as absent or present. 


\section{Time to Diagnosis}

We determined the time in minutes from ER arrival, i.e., first log-in of the MTS nurse for patient triage, to the moment of completion of the neurologist's report in the hospital's digital information system.

\section{DATA ANALYSIS}

IBM SPSS Statistics 22 was used for data analysis. To evaluate demographic and clinical differences between groups, chi-square tests for homogeneity with post-hoc Bonferroni corrected $z$-tests were used. When the sample size assumption was not met, a Fisher's exact test with, when necessary, Monte Carlo simulation $(10,000)$ was conducted instead. For between-group comparisons of continuous variables, one-way ANOVAs with post-hoc tests were conducted. To adjust for multiple comparisons, Tukey's honest significance difference or Games-Howell was used. The sample distribution was balanced with an almost equal number of observations in each group, thus one-way ANOVA was considered robust against any non-normality $(20,21)$.

\section{RESULTS}

\section{Demographic Data}

We identified 100 refugee patients (R-patients, 75\% male, mean age 33.2 years \pm 1.3 , Table 1 ) who had presented to the ER with neurological symptoms. ER-Presentation of R-patients was not equally distributed across the study period, but rather showed a peak in January 2016, i.e., shortly after the peak of arrivals of asylum seekers in Germany (Figure 1).

Demographics of R-patients did not correspond to the average distribution of age and gender of neurological ER-patients. Compared to demographical data from a previous study in the same ER (21), R-patients were younger and more often male. We therefore matched $\mathrm{M}$ - and $\mathrm{N}$ - patients presenting during the same study period as closely as possible for age and gender to R-patients $(p=0.777$ and $p=0.075$ difference between groups, Table 1). For the M-group, we identified 96 patients with an immigrant background (63\% male, mean age 34.5 years \pm 1.2). For the N-group, we found 95 patients without immigrant background fulfilling inclusion criteria for our study (61\% male, mean age 33.6 years \pm 1.4 ).

\section{Triage on Admission}

We found no significant differences in the distribution of MTS classes between groups (Table 1, Figure 2). The majority of patients in either group were assigned to class "yellow" (should see a physician within $30 \mathrm{~min}$ ) and "green" (should see a physician within $90 \mathrm{~min}$ ). Thus, on admission, R-patients received a medical prioritization by nursing staff that did not differ from the other two groups.

\section{Complaints on Admission}

Headache was the most frequent complaint in all three patient groups. However, consistent with previous studies of sociocultural influences on neurological chief complaints (22), this symptom was more frequent in R-patients (37.8\%) and $\mathrm{M}$ patients $(42.7 \%)$ compared to $\mathrm{N}$-patients (24\%). The second most common complaint in R-patients was a seizure-like event (25.2\%). The frequency of this complaint in R-patients differed significantly from the other groups (M-patients $4.2 \%, p<0.05$; $\mathrm{N}$-patients 7.4\%, $p<0.05$ ). Dizziness was common and occurred at a similar frequency in all groups (M-patients $18.2 \%$; Npatients $18.9 \%$; R-patients $13.3 \%$ ). Less frequent complaints on admission were somatosensory impairments, paresis, definite seizures (patients with an established diagnosis of epilepsy), decreased vigilance, cranial nerve disorders (Bell's palsy), and psychiatric disorders (Table 2).

\section{Diagnoses at Discharge}

The pattern of diagnoses at discharge from the ER differed significantly between groups $\left[\chi_{(2)}^{2}=67.6, p=0.001\right.$ Table 2]. A frequent diagnosis in the R-patients was headache of unknown etiology (11.0\%). This diagnosis was significantly more often assigned to R-patients than to $\mathrm{N}$-patients $(1.1 \%$; $p<0.05)$. Likewise, a diagnosis of non-epileptic (i.e., psychogenic) seizures was significantly more often assigned to R-patients than to $\mathrm{M}$ patients and N-patients (11.0 vs. 2.1 and vs. $2.1 \%$, respectively, both $p<0.05)$. By contrast, symptomatic epileptic seizures occurred less often in R-patients (4.0\%) and M-patients (1.0\%) compared to N-patients (8.4\%). Psychiatric diagnoses other than non-epileptic seizures were seen in $9.0 \%$ of R-patients, in $4.2 \%$ of M-patients and $5.3 \%$ of $\mathrm{N}$-patients. Thus, the combined frequency of non-epileptic seizures and other psychiatric disorders was significantly higher in R-patients $(20.0 \%)$ than in M-patients $(6.3 \%, p<00.05)$ and N-patients $(7.4 \%, p<0.05)$. Conversely, the combined frequency of serious neurological disorders requiring immediate in-hospital treatment (stroke and multiple sclerosis) was significantly lower in R-patients $(9.0 \%)$ than in N-patients $(27,3 \%, p<0.05)$, but not different from M-patients $(12.5 \%, p>0.05)$.

\section{Length of Medical History and Examination}

Medical histories were longer in R- and M-patients compared to $\mathrm{N}$-patients ( $p=0.006$ and $p=0.002$, respectively, Table 1 ). By contrast, length of physical examination records did not differ between groups, indicating that refugees received a similar medical attention as the other two groups (Table 1).

\section{CT, MRI, Blood Analyses, and Lumbar Puncture}

Cranial imaging (CT, MRI) was performed at a similar frequency in all three groups (R-patients 53.0\%; M-patients 49.0\%; Npatients 56.8\%; Table 1). However, consistent with the different pattern of diagnoses at discharge from the ER, R-patients received significantly less often MRI (16.0\%) compared to N-patients $(30.5 \% ; p=0.041)$. No significant difference in the number of MRIs was found compared to M-patients $(28.0 \% ; p=0.057)$. Blood analyses were performed at a similar frequency across groups (R-patients 89.0\%; M-patients 94.8\%; N-patients $92.6 \%$; Table 1). Likewise, we found no significant differences between frequencies of lumbar punctures across groups (R-patients $9.0 \%$; M-patients 15.6\%; N-patients 11\%; Table 1). 
TABLE 1 | Demographical data and medical management of patients.

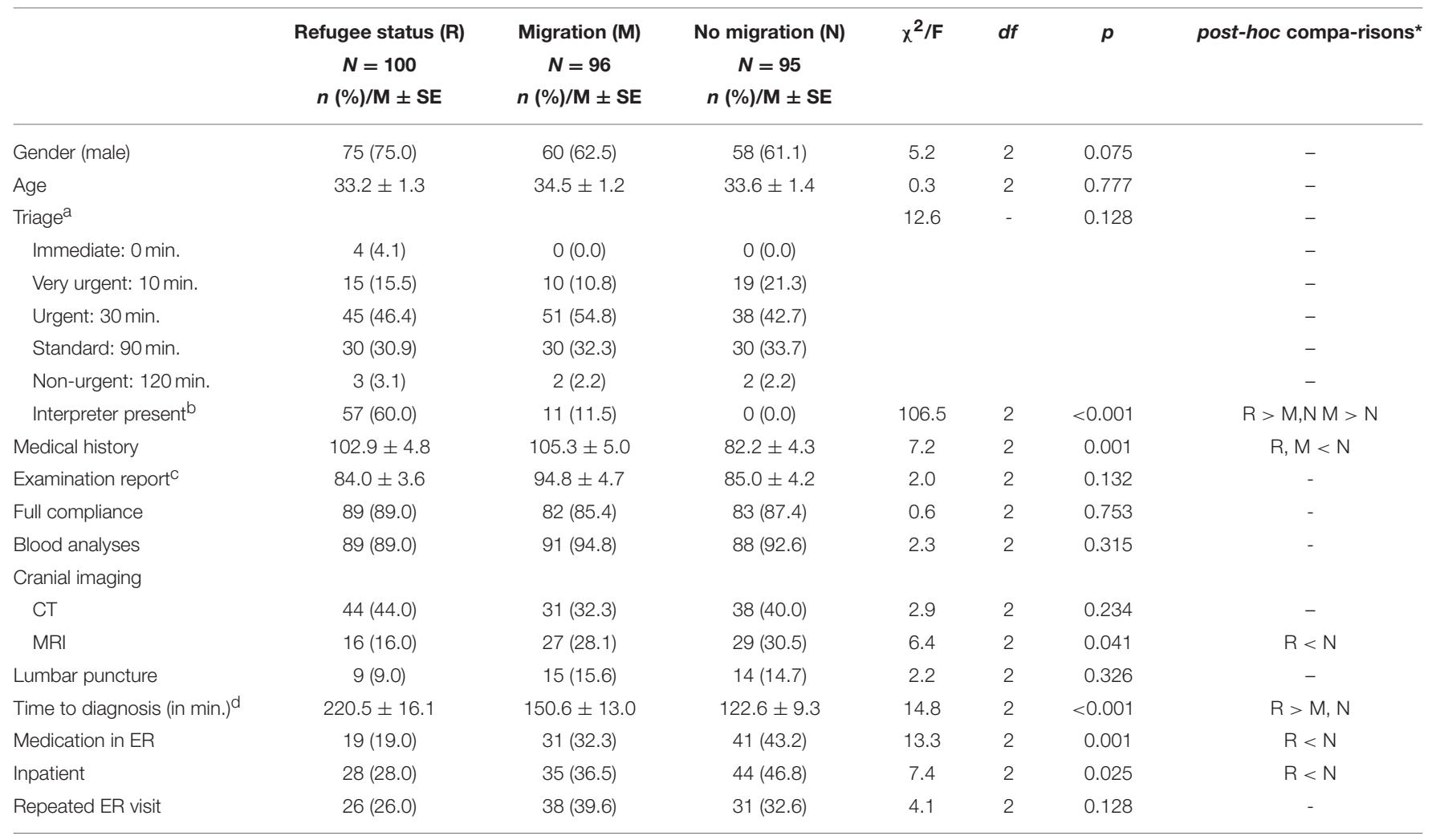

${ }^{*} p=0.05$, Bonferroni corrected post-hoc z-tests for chi-square or Tukey's honest significance difference or Games-Howell post-hoc tests for ANOVA.

${ }^{a} n_{R}=97, n_{M}=93, n_{N}=89$.

${ }^{b} n_{R}=95$.

${ }^{c} n_{N}=94$.

${ }^{d} n_{R}=99, n_{M}=94$.
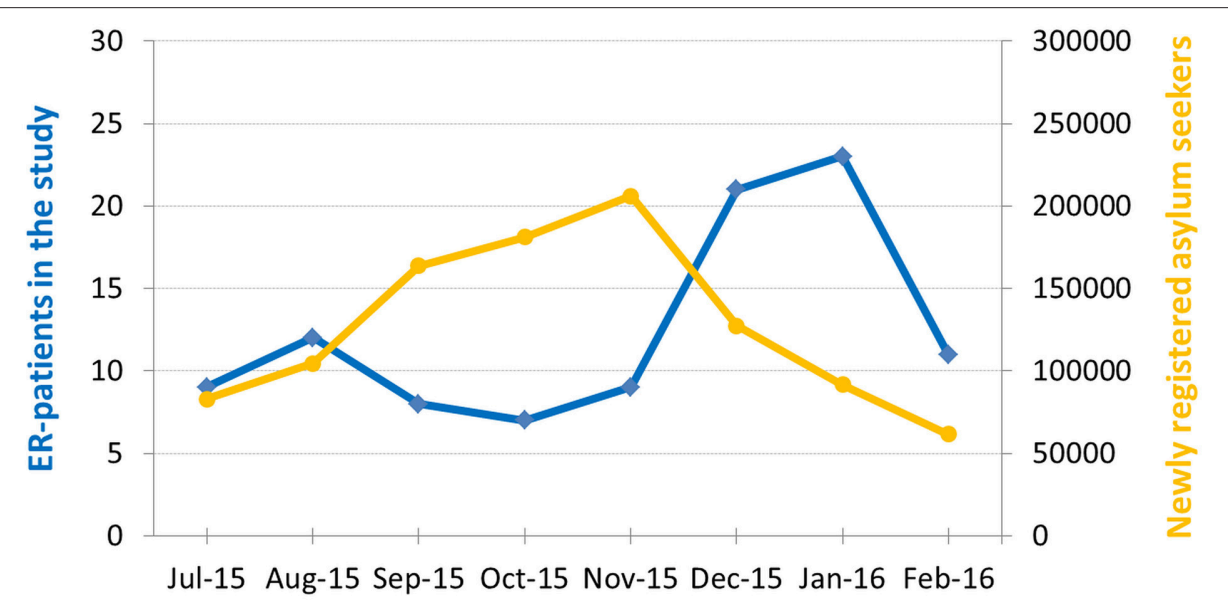

FIGURE 1 | Number of ER-patients with refugee status (blue) and number of first registrations of asylum seekers in Germany (yellow) during the recruitment period (16). Note peak of ER-patients with refugee status immediately after peak of registrations.

\section{Interpreters}

In most R-patients, communication and history taking was not sufficiently possible in English. Thus, an interpreter was present during management of $60.0 \%$ of R-patients (29\% were professional interpreters), whereas only $11.5 \%$ of $\mathrm{M}$-patients were interviewed with the help of an interpreter (2\% were 


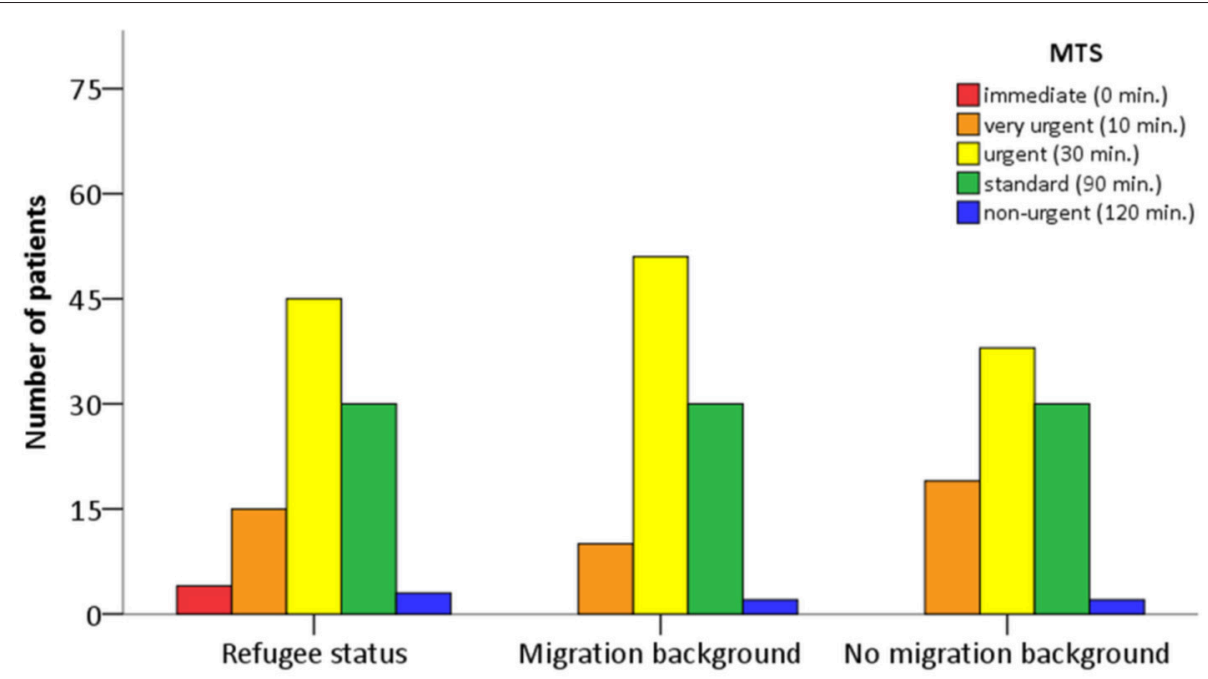

FIGURE 2 | Manchester Triage (MTS) of patient groups on admission.

professional interpreters) (Table 1). In N-patients, interpreters were not called upon.

\section{Time to Diagnosis}

Although the clinical work-up was similar across groups, time to diagnosis showed large and significant differences. R-patients spent significantly more time in the ER with a mean stay of $220 \mathrm{~min}$ compared to $151 \mathrm{~min}$ in M-patients and $123 \mathrm{~min}$ in $\mathrm{N}$-patients (Table 1).

\section{Pharmacological Treatment in the ER and Further In-hospital Treatment}

R-patients received significantly less often pharmacological treatment in the ER than M-patients and N-patients $(19.0 \%$ compared to 32.3 and $43.2 \%$, respectively; $p<0.05$ for both comparisons). Consistent with the different pattern of diagnoses at discharge, R-patients also received less often further in-hospital treatment $(28.0 \%)$ than $\mathrm{N}$-patients $(46.8 \%$; $p<0.05)$.

\section{DISCUSSION}

We report the neurological symptoms of newly arrived refugees presenting to the ER of a large university hospital. This group of patients differs in several respects from the average patient population seen by European neurologists. Refugee patients presented with a spectrum of neurological disorders that is only partly explainable with cultural differences relative to the native patient population. We found a higher number of psychiatric diagnoses, in particular non-epileptic seizures, and a lower number of neurological emergencies requiring immediate in-hospital treatment. Moreover, most diagnoses mainly depended on thorough history taking rather than on physical examination.

Although recruited during the peak of refugee arrivals in Germany, the patient sample studied here is small, in particular in comparison to previous large studies of neurological disorders in refugee camps in non-European countries $(11,23,24)$. The epidemiology of the populations in these studies differs importantly from our sample that consisted mostly of young male adults and did not include children and adolescents. Rather, our sample closely matches the demographical structure of immigrants as registered in 2015 in Greece and Italy, i.e.., the main first destinations for refugees in Europe (25, 26). However, the unique social and political constellation in Germany in autumn 2015 allowed us to study whether forced migration affects the spectrum of neurological emergencies as seen in a European emergency department. These effects are usually difficult to disentangle from cultural influences on neurological symptoms $(27,28)$. We have therefore deliberately restricted our analysis to patients for whom medical records unequivocally documented an actual refugee status.

Consistent with previous studies, the most frequent neurological complaint on admission in all three groups was headache, with particularly high numbers in patients with immigrant background with and without refugee status $(22,29)$. Diagnoses differed however between groups. Refugees were mostly discharged with a diagnosis of headache of unknown etiology, whereas patient with migrational background and natives were mostly discharged with a diagnosis of migraine. This is obviously not the result of less thorough history taking or medical prejudices of emergency neurologists (30), as histories were longer in refugees and immigrant background patients compared to controls. Since both immigrant groups shared a similar cultural background and the prevalence of migraine in Arab countries does not differ from worldwide estimates (31), these differences are thus likely to result from difficulties in communication between emergency neurologist and patient.

The second most frequent complaint on admission in refugees were seizures or seizure-like symptoms. These symptoms 
TABLE 2 | Neurological complaints on admission and diagnoses at discharge.

\begin{tabular}{|c|c|c|c|c|c|c|}
\hline & $\begin{array}{l}\text { Refugee status (R) } \\
\qquad \begin{array}{c}N=100 \\
n(\%)\end{array}\end{array}$ & $\begin{array}{c}\text { Migration (M) } \\
\begin{array}{c}N=96 \\
n(\%)\end{array}\end{array}$ & $\begin{array}{c}\text { No migration (N) } \\
\begin{array}{c}N=95 \\
n(\%)\end{array}\end{array}$ & $x^{2}$ & $p$ & post-hoc compa-risons* \\
\hline Complaints on admission & & & & $45.1^{\mathrm{a}}$ & 0.001 & \\
\hline Headache & $37(37.8)$ & $41(42.7)$ & $23(24.2)$ & & & $M>N$ \\
\hline Dizziness & $13(13.3)$ & $18(18.2)$ & $18(18.9)$ & & & n.s. \\
\hline Possible seizure & $25(25.2)$ & $4(4.2)$ & $7(7.4)$ & & & $R>M, N$ \\
\hline Definite seizure & $2(2.0)$ & $5(5.2)$ & $8(8.4)$ & & & n.s. \\
\hline Paresis & $6(6.1)$ & $4(4.2)$ & $8(8.4)$ & & & n.s. \\
\hline Somatosensory impairments & $7(7.1)$ & $9(9.4)$ & $15(15.8)$ & & & n.s. \\
\hline Decreased vigilance & $5(5.1)$ & $4(4.2)$ & $3(3.2)$ & & & n.s. \\
\hline Cranial nerve disorders & $3(3.1)$ & $10(10.4)$ & $10(10.5)$ & & & n.s. \\
\hline Psychiatric disorder & $0(0.0)$ & $0(0.0)$ & $3(3.2)$ & & & n.s. \\
\hline Dementia & $0(0.0)$ & $1(1.0)$ & $0(0.0)$ & & & n.s. \\
\hline Diagnoses at discharge & & & & $67.6^{\mathrm{a}}$ & 0.001 & \\
\hline Headaches & $n=33$ & $n=34$ & $n=26$ & & & \\
\hline Migraine & $5(5.0)$ & $13(13.5)$ & $11(11.6)$ & & & n.s. \\
\hline Tension-type headache & $3(3.0)$ & $8(8.3)$ & $5(5.3)$ & & & n.s. \\
\hline Trigeminal-autonomic headaches & $3(3.0)$ & $1(1.0)$ & $1(1.1)$ & & & n.s. \\
\hline Parainfectious headache & $8(8.0)$ & $2(2.1)$ & $5(5.3)$ & & & n.s. \\
\hline Other symptomatic headaches & $8(8.0)$ & $2(2.1)$ & $3(3.2)$ & & & n.s. \\
\hline Headache of unknown etiology & $11(11.0)$ & $8(8.3)$ & $1(1.1)$ & & & $\mathrm{R}>\mathrm{N}$ \\
\hline Seizures and related disorders & $n=29$ & $n=13$ & $n=20$ & & & \\
\hline Non-epileptic seizure & $11(11.0)$ & $2(2.1)$ & $2(2.1)$ & & & $\mathrm{R}>\mathrm{M}, \mathrm{N}$ \\
\hline Seizure & $7(7.0)$ & $5(5.2)$ & $7(7.4)$ & & & n.s. \\
\hline Symptomatic epileptic seizure & $4(4.0)$ & $1(1.0)$ & $8(8.4)$ & & & $\mathrm{M}<\mathrm{N}$ \\
\hline Syncope & $7(7.0)$ & $5(5.2)$ & $3(3.2)$ & & & n.s. \\
\hline Other & $n=33$ & $n=37$ & $n=42$ & & & n.s. \\
\hline Psychiatric diagnosis & $9(9.0)$ & $4(4.2)$ & $5(5.3)$ & & & n.s. \\
\hline Multiple sclerosis & $5(5.0)$ & $5(5.2)$ & $14(14.7)$ & & & n.s. \\
\hline Stroke & $4(4.0)$ & $7(7.3)$ & $12(12.6)$ & & & n.s. \\
\hline Dizziness of unknown etiology & $3(3.0)$ & $7(7.3)$ & $4(4.2)$ & & & n.s. \\
\hline $\begin{array}{l}\text { Benign paroxysmal positional } \\
\text { vertigo }\end{array}$ & $4(4.0)$ & $1(1.0)$ & $1(1.1)$ & & & n.s. \\
\hline Cranial nerve palsy & $1(1.0)$ & $8(8.3)$ & $4(4.2)$ & & & n.s. \\
\hline Other discipline & $7(7.0)$ & $5(5.2)$ & $2(2.1)$ & & & n.s. \\
\hline Miscellaneous disorders ${ }^{b}$ & $5(5.0)$ & $11(11.5)$ & $7(7.4)$ & & & n.s. \\
\hline
\end{tabular}

${ }^{\star} p=0.05$, Bonferroni corrected post-hoc z-tests. n.s, not significant.

a Fisher's exact test with Monte Carlo simulation $(10,000)$ when necessary.

${ }^{b}$ metabolic diseases, motoneuron disease, myasthenia gravis, neuritis vestibularis, peripheral nerve affection, pseudotumor cerebri, psychoorganic syndrome.

occurred at a significantly higher frequency than in the other two groups. On the first glance, our results thus seem to confirm previous reports of a particularly high number of epilepsy patients in refugee camps outside Europe $(10,11)$. It has been speculated that this may reflect both an increased frequency of CNS disorders such as perinatal injury, genetic diseases, malnutrition, infectious diseases, previous stroke and direct consequences of war and conflict such as head trauma $(23,24,32)$. The patient sample in our study did not present with an increased frequency of these disorders. Instead, we found a significant percentage of patients fulfilling the diagnostic criteria for "possible" or "probable" psychogenic non-epileptic seizures (33). The discrepancy to the aforementioned studies may point to the fact that refugees arriving in European countries often represent a selection of comparatively healthy young males that have received support from their families for migration to Europe (26). Conversely, children, women, older family members, and people with disorders of the CNS are less apt to cope with the stress and dangers of an-often illegal-journey to Europe. It is therefore not surprising that we found a low number of stroke patients in our sample, although cerebrovascular disease is considered to be a major neurological issue in refugee camps outside Europe (24).

Current pathogenetic concepts suggest that not only childhood trauma, but also trauma in adult life may be a precipitating factor that may trigger psychogenic non-epileptic 
seizures (34). Since the ethnic and cultural background of refugees and immigrant controls was similar, we deem a traumarelated mechanism relating to the causes for migration or to migration itself the likeliest explanation for the high number of psychogenic non-epileptic seizures. Together with other psychiatric diagnoses, this disorder accounted for $20 \%$ of all diagnoses on discharge. Conversely, none of the patients had presented with an established diagnosis or a suspicion of a psychiatric disorder on admission, thus suggesting that these diagnoses were established for the first time during the visit in the emergency department. It has been shown repeatedly that refugees frequently suffer from post-traumatic stress disorder (PTSD) and affective disorders $(8,9,35)$. Moreover, there appear to be close pathophysiological links between psychogenic non-epileptic seizures and PTSD (34). For both disorders, early cognitive behavioral therapy is the mainstay of treatment (34, 36-38). Unfortunately, most neurological residents were not able to pave the way to appropriate and cultural competent follow-up care for refugee patients during the short stay in the emergency department.

Surveys in Western countries have repeatedly shown a great willingness of residents to care for diverse sociocultural patient groups, including immigrants and refugees [eg., (15, 39)]. However, most physicians also face major obstacles when caring for refugees, including language barriers, cultural differences, health concepts that differ from Western medicine, time constraints and lack of knowledge about medical disorders in the country of origin $(9,15,39)$. Thus, many physicians do not feel sufficiently prepared for cross-cultural medical care $(15,39)$. Conversely, refugees often struggle with a lack of knowledge of the health system in Western countries, language barriers, lack of understanding of diagnostic tests and treatment recommendations and with difficult physician-patient relationships $(9,30)$. For example, in addition to a perceived lack of respect and valuation by some physicians, one repeated concern is that overly empathic physicians offer unjustified psychological explanations for physical complaints (30). Since we have no systematic follow-up data for our patients, it is indeed difficult to rule out definitely that the high percentage of psychiatric disorders is a result of misdiagnosis of primary neurological disorders, in particular epilepsy. On the other hand, our data are not indicative of any positive or negative bias toward refugee patients. Refugees were triaged like the other two patient groups, received the same attention during history taking and physical examination and underwent a similar diagnostic workup, including cranial imaging. Full compliance with diagnostic procedures and therapeutic recommendations was observed with the same frequency as in the other two groups. However, our data also show that the entire management of neurological patients with refugee status nevertheless requires significantly more time and resources as in patients with immigrant background but established German residency and as in native Germans. Despite the ubiquity of English language in popular culture throughout the world, clinical management critically dependent on the presence of an interpreter in most cases, suggesting that low English proficiency contributed significantly to the total duration of stay in our emergency department. Despite the use of interpreters, significant uncertainties in communication remained that may have contributed to less MRIs/more CTs in refugees and a lower rate of immediate pharmacological treatment at discharge.

\section{CLINICAL IMPLICATIONS}

The data presented here are a first neurological snapshot of a growing medical topic that will increasingly occupy neurologists in Western countries and that has hitherto not been part of resident training. Although the period investigated in our study may have been unique so far, the persistence of armed conflicts in the Great Middle East and other regions of the world increases the likelihood of further waves of forced migration. Neurologists must be aware that refugee patients present with a spectrum of emergencies and management problems that partly transcend the self-evident competences of physicians working in a multi-cultural metropolitan environment. They must be prepared to take responsibility for patients with neuropsychiatric diagnoses such as psychogenic non-epileptic seizures or PTSD that are likely consequences of conflicts and migration. These diagnoses need early and culturally competent follow-up interventions-also because they may present obstacles for integration in the country of resettlement. Emergency departments therefore need to take into account the resources that are required to organize further treatment and to reduce diagnostic uncertainties in refugees with neuropsychiatric disorders. This may be facilitated with the use of native-language questionnaires for the most frequent neurological complaints (e.g., headache, seizures, vertigo), trauma rating scales and the availability of professional interpreters. Standard operating procedures and contacts for subsequent qualified in- and out-ofhospital treatment should be available to emergency physicians and neurologists delivering primary care for this particular patient group. Most importantly, the perspective of refugees on medical care should be evaluated systematically and integrated into training of emergency neurologists.

\section{DATA AVAILABILITY STATEMENT}

The data supporting the conclusions of this manuscript will be made available by the authors to any qualified researcher.

\section{AUTHOR CONTRIBUTIONS}

MB was involved in study design, acquired all data, and drafted the manuscript. BvN performed statistical analyses. CL provided important methodological advice and revised the manuscript for intellectual content. CP designed and supervised the study and drafted the manuscript. 


\section{REFERENCES}

1. UNHCR-2015 Likely to Break Records for Forced Displacement. (UNHCR's Mid-Year Trends 2015 Report). Available online at: http://www.unhcr. org/news/latest/2015/12/5672c2576/2015-likely-break-records-forceddisplacement-study.html (Accessed June 18, 2018).

2. Montero AL. The Impact of the Refugee Crisis on Local Public Social Services in Europe. The European Social Network (2016). Available online at: http:// www.esn-eu.org/news/821/index.html (Accessed June 18, 2018).

3. Europe Situation. Available online at: http://www.unhcr.org/europeemergency.html (Accessed June 18, 2018).

4. Social Protection Committee of the European Union - Annual Report (2017). p 41-3.

5. Bronstein I, Montgomery P. Psychological distress in refugee children: a systematic review. Clin Child Family Psychol Rev. (2011) 14:44-56. doi: 10.1007/s10567-010-0081-0

6. Weaver C, Sklar D. Diagnostic dilemmas and cultural diversity in emergency rooms. Western J Med. (1980) 133:356-66.

7. Fields A, Abraham M, Gaughan J, Haines C, Hoehn KS. Language matters: race, trust, and outcomes in the pediatric emergency department. Pediatric Emergency Care (2016) 32:222-6. doi: 10.1097/PEC.0000000000000453

8. Crosby S. Primary care management of non-english-speaking refugees who have experienced trauma. J Am Med Assoc. (2013) 310:519-28. doi: 10.1001/jama.2013.8788

9. Giacco D, Laxhman N, Priebe S. Prevalence of and risk factors for mental disorders in refugees. Semi Cell Dev Biol. (2018) 77:144-52. doi: 10.1016/j.semcdb.2017.11.030

10. Mateen FJ, Carone M, Haskew C, Spiegel P. Reportable neurologic diseases in refugee camps in 19 countries. Neurology (2012) 79:937-40. doi: 10.1212/WNL.0b013e318266fcf1

11. McKenzie ED, Spiegel P, Khalifa A, Mateen FJ. Neuropsychiatric disorders among Syrian and Iraqi refugees in Jordan: a retrospective cohort study. 2012-2013. Conflict Health (2015) 9:10. doi: 10.1186/s13031-015-0038-5

12. Lustig SL, Kia-Keating M, Knight WG, Geltman P, Ellis H, Kinzie JD, et al. Review of child and adolescent refugee mental health. J Am Acad Child Adol Psychiatry (2004) 43:24-36 doi: 10.1097/00004583-200401000-00012

13. Reed RV, Fazel M, Jones L, Panter-Brick C, Stein A. Mental health of displaced and refugee children resettled in low-income and middleincome countries: risk and protective factors. Lancet (2012) 379:250-65. doi: 10.1016/S0140-6736(11)60050-0

14. United Nations High Commissioner for Refugees. Displacement: The New 21st Century Challenge (2013). Avaialble online at: http://unhcr.org/ globaltrendsjune2013/UNHCR\%20GLOBAL\%20TRENDS\%202012_V05. pdf (Accessed June 15, 2018).

15. Alpern JD, Davey CS, Song J. Perceived barriers to success for resident physicians interested in immigrant and refugee health. BMC Med Edu (2016)16:178. doi: 10.1186/s12909-016-0696-z

16. Das EASY-Gap. Available online at: https://refugee-datathon-muc.org/archiv/ das-easy-gap/ (Accessed June 15, 2018).

17. Available online at: https://www.britannica.com/place/Afghanistan/ Languages (Accessed 06/18/2018).

18. Available online at: https://www.bamf.de/SharedDocs/Anlagen/DE/ Publikationen/Migrationsberichte/migrationsbericht-2015.html

19. Mackway-Kones K, Marsden J, Windle J. Emergency Triage: Manchester Triage Group. London: BMJ Publishing Group (1997)

20. Lix LM, Keselman JC, Keselman HJ. Consequences of assumption violations revisited: a quantitative review of alternatives to the one-way analysis of variance "F" test. Rev Edu Res. (1996) 66:579-619

21. Maxwell SE, Delaney HD. Designing Experiments and Analyzing Data: A Model Comparison Perspective. 2nd edn. London: Lawrence Erlbaum Associates (2004).

22. Royl G, Ploner CJ, Leithner C. Headache in the emergency room: the role of immigrant background on the frequency of serious causes and diagnostic procedures. Neurol. Sci. (2012)33:793-9. doi: 10.1007/s10072-011-0830-y

23. Mateen FJ. Neurological disorders in complex humanitarian emergencies and natural disasters. Ann Neurol. (2010) 68:282-94. doi: 10.1002/ana.22135
24. Mateen FJ. Medical conditions among Iraqi refugees in Jordan: data from the United Nations Refugee Assistance Information System. Bull World Health Organ (2012) 90:444-51 doi: 10.2471/BLT.11.097048

25. Mediterranean Western Balkans Update - New Numbers from Italy, Greece, the FYROM. Available online at: https://www.iom.int/news/mediterraneanwestern-balkans-update-new-numbers-italy-greece-fyrom

26. Bundesamt für Migration und Flüchtlinge: Worbs S Asyl - Und dann? (2016) Available online at: https://www.bamf.de/SharedDocs/Anlagen/DE/ Publikationen/Forschungsberichte/fb28-fluechtlingsstudie-2014.pdf?_ blob=publicationFile

27. Sulaiman-Hill C, Thompson SC. Sampling challenges in a study examining refugee resettlement. BMC Int Health Human Rights (2011) 11:2. doi: 10.1186/1472-698X-11-2

28. Enticott JC, Shawyer F, Vasi S, Buck K, Cheng IH, Russell G et al. A systematic review of studies with a representative sample of refugees and asylum seekers living in the community for participation in mental health research. BMC Med Res Methodol. (2017) 17:37. doi: 10.1186/s12874-017-0312-x

29. Royl G, Ploner CJ, Möckel M, Leithner C. Neurological chief complaints in an emergency room Nervenarzt. (2010) 81:1226-30. doi: 10.1007/s00115-010-3020-x

30. Cheng IH, Drillich A, Schattner P. Refugee experiences of general practice in countries of resettlement: a literature review. Br J Gen Pract. (2015) 65:e171-6. doi: 10.3399/bjgp15X683977

31. Benamer HT, Deleu D, Grosset D. Epidemiology of headache in Arab countries. J Headache Pain. (2010) 11:1-3. doi: 10.1007/s10194-0090173-8

32. Kane JC, Ventevogel P, Spiegel P, Bass JK, van Ommeren M, Tol WA. Mental, neurological, and substance use problems among refugees in primary health care: analysis of the health information system in 90 refugee camps. BMC (2014) 12:228 doi: 10.1186/s12916-014-0228-9

33. LaFrance C, Baker GA, Duncan R, Goldstein LH, Reuber M. Minimum requirements for the diagnosis of psychogenic non-epileptic seizures: a staged approach. Epilepsia (2013) 54:2005-18. doi: 10.1111/epi. 12356

34. Kanemoto K, LaFrance C, Duncan R, Gigineishvili D, Park, SP, Tadokoro Y et al. (2017) PNES around the world: Where we are now and how we can close the diagnosis and treatment gaps - an ILAE PNES Task force report. Epilepsia Open (2017) 2:307-16. doi: 10.1002/epi4.12060

35. Weisleder P, Rublee C. The Neuropsychological consequences of armed conflicts and torture. Curr Neurol Neurosci Rep. (2018) 18:9. doi: 10.1007/s1 1910-018-0818-6

36. Qi W, Gevonden M, Shalev A. Prevention of post-traumatic stress disorder after trauma: current evidence and future directions. (2016) 18:20. doi: 10.1007/s11920-015-0655-0

37. Birur B, Moore NC, Davis LL. An evidence-based review of early intervention and prevention of posttraumatic stress disorder. Community Ment Health J. (2017) 52:13-201. doi: 10.1007/s10597-016-0047-x

38. Ross DA, Arbuckle MR, Travis MJ, Dwyer JB, van Schalkwyk GI, Ressler KJ. (2017) An integrated neuroscience perspective on formulation and treatment planning for posttraumatic stress disorder. an educational review. JAMA Psychiatry (2017) 74:407-15

39. Weissmann JS, Betancourt J, Campbell EG, Park ER, Kim M, Clarridge B, et al. (2005) Resident physicians' preparedness to provide cross-cultural care. J Am Med Assoc (2005) 294:1058-67. doi: 10.1001/jama.294.9.1058

Conflict of Interest Statement: The authors declare that the research was conducted in the absence of any commercial or financial relationships that could be construed as a potential conflict of interest.

Copyright (C) 2018 Brinckmann, van Noort, Leithner and Ploner. This is an openaccess article distributed under the terms of the Creative Commons Attribution License (CC BY). The use, distribution or reproduction in other forums is permitted, provided the original author(s) and the copyright owner(s) are credited and that the original publication in this journal is cited, in accordance with accepted academic practice. No use, distribution or reproduction is permitted which does not comply with these terms. 